\title{
Dynamic Winner-take-all Conflict
}

\author{
John W. Maxwell \\ Kelley School of Business \\ Indiana University \\ Rafael Reuveny \\ School of Public and Environmental Affairs \\ Indiana University \\ Jefferson Davis \\ Stat-Math \\ Indiana University
}

\begin{abstract}
This paper develops a model of dynamic conflict featuring probabilistic winnertake-all outcomes and compares its behavior to a model in which combatants emerge with a share of the conflict spoils. While these two models generate the same behavior in a one-shot game, we find that in a repeated conflict setting the winner-take-all model generates richer dynamics than the dynamics generated by the share model. Differences include outcomes that illustrate the rise and fall of great powers, the endogenous extinction of combatants, and frequent changes in the relative dominance of combatants. The model's behavior is compared to real world military, business and political conflict outcomes.
\end{abstract}

JEL Numbers: D74, Q20

Keywords: Anarchy, Fog of War, Paradox of Power, Winner-take-all Conflict 


\section{Introduction}

This paper develops a model of dynamic conflict that captures two elements frequently observed in real world conflict: "the fog of war" and the "paradox of power." The fog of war is a term coined by military philosopher Karl von Clausewitz to describe the confusion that arises when commanders must make critical decisions based on fragmentary and often contradictory information. Under these circumstances even the most seasoned commanders in charge of dominant militaries can make mistakes that result in defeat. The paradox of power (POP) is a term coined by Jack Hirshleifer (1991) to describe the phenomenon in which a resource-rich actor obtains a share of conflict spoils that is equal to that of his resource-poor rival - hence, the paradox. Explaining this outcome, Hirshleifer shows that the weaker actor mobilizes more resources toward conflict than does the stronger actor. If the mobilized resources are people of two countries, for example, this would mean that the smaller country allocates disproportionately more of its people to fighting than the larger country. As a result, it reaches parity with the opposing group on the battlefield, either winning the same share of the conflict spoils, or facing an equal probability of victory.

Our model captures two elements of conflict: probabilistic winner-take-all outcome the fog of war - and disproportional mobilization of fighting resources - the POP. While probabilistic, it is important to note that the winner-take-all nature of conflict in our model is not purely stochastic. The rivals' probabilities of success are rising in the relative levels of resources they devote towards conflict. The POP aspect of the encounters drives weaker actors to allocate more of their resources to fighting facing stronger opponents. Weaker combatants are more likely to lose. However, the outcome of the battle is never guaranteed; a weaker rival always faces a positive probability of victory. The combination of these elements in a dynamic setup generates rich dynamics that, so far, have not been observed in the economic literature on conflict and are indicative of many aspects of real world conflicts.

Our study has important implications for many classes of models that feature competition between agents, not only those that involve military engagements. The most common form of conflict in economic models, be it military conflict, contests to influence political outcomes, or R\&D races, is based on a Tullock-style contest success function. ${ }^{1}$ This function is often assumed to capture, interchangeably and simultaneously, two distinct approaches to conflict.

\footnotetext{
${ }^{1}$ For examples from the conflict literature, see e.g., Hirshleifer (1989) and Garfinkel and Skaperdas (2000). Nitzan (1994) surveys the use of this function in the public choice literature. For an example of the use of the this function in the research and development literature, see Fullerton and McAfee (1999). Baye and Hoppe (2003) show that various rent-seeking contests, innovation tournaments and patent race games are strategically equivalent to games based on the Tullock-Style Function.
} 
The first, which we label the win approach, assumes that a single combatant wins all of the conflict spoils with a given probability that depends on the relative level of resources devoted to the competition. We compare this approach to the share approach, which assumes that each combatant emerges with a share of the conflict spoils determined by the relative level of resources each combatant devotes to the competition.

In almost all of these applications, conflict has been modeled as a one-shot game. ${ }^{2}$ In this case, the two approaches lead to the same level of expected returns from the conflict, and so lead competitors to undertake the same strategic actions in an attempt to maximize their expected returns. While one may be interested in non-repeated competitions, repeated competition is common. Businesses often face each other repeatedly in the battle for sales, and often engage in multiple patent races. Winning an important client or winning a patent race may allow the firm to be in a stronger position vis a vis its rivals in future battles. Wars usually consist of a series of battles, and the same nations often go to war repeatedly. Lobbyists may face each other repeatedly over legislative initiatives that deal with a common topic, such as the environment. Political parties battle repeatedly in election after election, etc. In all of these cases, the actors do not have property rights over the disputed resource (be it a patent, territory, or voters' support), a point to which we will return in the next section.

While the share and win approaches to conflict can be viewed as interchangeable in a static setting, we show that they differ in a dynamic setting. Thus, the researcher must think carefully about the specific form of conflict he or she wishes to assume once repeated interactions are considered. ${ }^{3}$

Previewing our findings, conflict based on the win approach leads to much richer dynamics than the share approach in a repeated setting, and fits better several features of real world conflict. The key difference between the two approaches is that, although they lead to similar expected returns, they generate different actual returns. In a model of repeated competition, it is the actual return that affects the future behavior of players. Not only do the two approaches lead to differences along any given dynamic path, they also result in systematic differences on average.

\footnotetext{
${ }^{2}$ We know of only two exceptions to this generalization, Reuveny and Maxwell (2001) and Maxwell and Reuveny (2004), to which we will turn shortly.

${ }^{3}$ In and of itself, this modeling decision will not always be clear. For example, one could assume that a battle over land might result in a splitting of the disputed territory between the rival groups. Alternatively one could assume that battles over the territory lead to decisive victories, and that the war consists of a series of battles of this type.
} 
One could argue that it is not surprising that the introduction of randomness into conflict outcomes will generate complex dynamic paths, but this characterization of our results would be too naive. A striking feature of our outcomes under the win approach is their "stability" in the sense of the very small number of deaths. This result highlights the importance of the interplay between the POP and the fog of war. The POP dictates that as long as a weaker actor does not face resource constraints, it will face an equal chance of victory. This is a stabilizing factor; absent the POP, the resource rich actor will (on average) continue to become stronger and eventually overwhelm and kill the enemy. The fog of war is also a stabilizing factor in the sense that the weaker actor always faces a positive probability of winning enough battles to regain a position of relative equality with its initially stronger foe. From this position, the weaker actor may go on to attain dominance over its rival.

The remainder of this paper is organized as follows. In section 2 we provide several motivating examples of military and non-military conflict, which highlight the important role that the fog of war and the POP play in in the real world. In section 3 we discuss how our approach contributes to the economic literature on conflict. In section 4 we present the win and share approaches conflict in a dynamic setting. We apply the two approaches to conflict over renewable resources in section 5, and we compare and contrast their conflict dynamics in section 6 . Section 7 summarizes our findings and suggests several avenues for future research.

\section{Motivating examples}

Powerful nations, armies, corporations, and political parities sometimes lose important battles that can be key to their eventual downfall. Historians tend to attribute these upsets to errors in strategy, military innovations, or logistical failures. In some cases, however, these upsets are unexplained and are often attributed to the fog of war. Consider, for example, the World War II U.S. - Japanese Battle over Midway Island. ${ }^{4}$ Prior this battle, Japan had won several battles in the Pacific against the US and its coalition. The Japanese struck first in the battle of Midway, inflicting wide-scale damages on the island. However, a critical piece of luck in the American's favor affected the outcome of the battle. The American scout-planes spotted the Japanese armada before the Japanese scout planes found the American fleet. This allowed the much smaller American navy to launch its attack at what turned out to be, again by chance, exactly the right time.

During their initial attack on the Island, the Japanese fighter planes radioed back to their

\footnotetext{
${ }^{4}$ See, e.g., Prange (1983) and Jablonski (1995).
} 
commanders that a second attack was desirable. Taking this action required the retrofitting of aircraft to carry bombs instead of torpedoes. After the retrofitting had begun, a Japanese scout plane spotted the American fleet. Japanese commanders faced a decision: should they continue retrofitting their planes to bomb Midway, or should they stop the activity and attack the American fleet with torpedoes? During the debate over this decision, the Americans launched an attack. The Japanese repelled it decisively, and the decision to attack Midway was taken. With their aircraft carriers full of planes being retrofitted, and fighters being refueled from the battle that had just ended, a second American attack came. The Japanese were essentially defenseless. The American navy handed the Japanese a crippling defeat that halted their relentless expansion throughout the Pacific. If the American scout-planes had not spotted the Japanese armada when they did, or had the Japanese not decided to retrofit their planes, the Battle of Midway might have turned out very differently.

Consider next the Battle of Stalingrad. ${ }^{5}$ The Germans arrived to Stalingrad in August 1942, following many victories. Their forces were stronger than the city's defenders, but the Russians mobilized and decided to fight to the last man. The battle soon turned into a stalemate. In November 1942, the Red Army surprised the Germans, attacking at the flanks some 100 miles to the west. Within a few days, German forces in Stalingrad became encircled. When the news arrived to German headquarters, some generals called for an immediate retreat from the city. Other generals argued that the encircled army could be supplied from the air until the siege would be broken from the outside. Hitler decided against retreat due to a "historical fluke." The city was renamed Stalingrad in honor of Stalin's success in fighting over it in the Russian civil war. For Hitler, Stalingrad became a synonym for Stalin; an obsession. The German attempt to supply the besieged army from the air failed. The encircled Germans yielded to the Russians at the end of January 1943. After Stalingrad, there would be more German victories, but the tied had shifted.

The Fog of War is not limited to military battles. The rise of Microsoft also seems to fit this mold. In the early stages of its personal computer development, executives of IBM contacted Bill Gates to discuss the state of home computers and Microsoft products. Gates, apparently uninterested in developing an operating system, suggested the executives consider the CP/M operating system written by Gary Kindall of Digital Research. IBM tried to contact Kindall, eventually meeting with his wife. She refused to sign a nondisclosure agreement. IBM returned to Gates and gave Microsoft a contract to develop an operating system. ${ }^{6}$ Had Mrs. Kindall signed the non-disclosure agreement the structure of the software

\footnotetext{
${ }^{5}$ See, e.g., Jablonski (1995) and Beevor (1999).

${ }^{6}$ Wallace and Erickson (1992).
} 
industry might be quite different today. In the political realm, there is much speculation regarding Howard Dean's upset loss in the 2004 Iowa primaries. Would Dean's Iowa loss have been as decisive without his infamous "I have a scream" speech, and the resulting media feeding frenzy?

History also provides examples of weaker nations fighting on a more level playing field than their resource disparities would otherwise suggest. The key to this "leveling" arises from weaker nations mobilizing more of their resources to conflict, which is the essence of the POP. For example, for many years Israel faced threats from virtually the whole Arab world. Yet, Israel prevailed time and again on the battlefield. The weaker North Vietnamese proved to be stronger opponents than the US initially expected. Nazi Germany and its allies had fewer resources than the opposing coalition, but emerged early on in the war as a dominant power. In each of these cases, the weaker combatant mobilized proportionally more of its resources to conflict than did its stronger rival. However, a greater mobilization of a nation's resources of war cannot guarantee victory. Germany eventually hit resource constraints; even with all of its resources devoted to conflict it could not overcome the onslaught of the much larger American and Soviet armies.

\section{A framework of anarchic conflict}

Our paper builds on the conflict literature in economics, which has arisen from the seminal work of Hirshleifer $(1988,1989)$. Hirshleifer's approach uses a one period game theoretic framework that augments the standard economic theory of production and exchange by treating wealth appropriation as a basic economic activity. Production is peaceful, whereas appropriation is conflictive. An underlying assumption of Hirshleifer's framework is that the disputed wealth lacks well-defined or enforceable property rights. Thus, a situation of anarchy prevails. Each actor's ultimate share of the contested wealth depends on its allocation of resources to appropriation. The contested wealth also depends on this allocation: the greater is the amount of resources allocated to conflict, the smaller is the amount of resources available for production of wealth. Each group maximizes its current wealth by allocating its resources among production and appropriation with this basic tension in mind.

Hirshleifer's framework has been extended in various ways, including differentiation between defensive and offensive activities, trade, and use of various forms of the contest success function. Each of these extensions employed Hirshleifer's one period framework. ${ }^{7}$ However,

\footnotetext{
${ }^{7}$ See, e.g., Hirshleifer (1995), Skaperdas (1992), Grossman and Kim (1995), Neary (1997), and Anderton et al. (1999).
} 
perhaps because of the static nature of these games, little attention has been paid to the role of the share and win interpretations of conflict.

The issue of conflict dynamics was considered in prior literature, but not based on Hirshleifer's framework. ${ }^{8}$ Hirshleifer (1995) took an initial step towards a dynamic approach through successive iterations of his one-shot setup, beginning with out-of-equilibrium resource allocations, and examined conditions that ensure convergence to equilibrium allocations. However, this approach is not dynamic in the usual sense. It does not specify equations of motion and time is not a variable in the model. Several authors in the conflict literature, including Hirshleifer, are aware of the limitations of the one shot setup, and have called for a fully dynamic extension of the basic framework (see e.g., Skaperdas, 1992; Hirshleifer, 1995; Grossman and Kim, 1995).

Reuveny and Maxwell (2001) and Maxwell and Reuveny (2004) have extended Hirshleifer's framework to a dynamic setting by modeling the interplay between the disputed wealth, production, and conflict over time. Their methodology is based on six assumptions. First, conflict spoils are invested so as to increase one's own fighting resources. These resources, which are not open to appropriation, are term captive. They can be thought of as the innate physical and human capital of the actors, which can be used for productive and conflictive activities. Second, a situation of anarchy prevails. Thus wealth, the production of which requires both captive and disputed resources, is open to appropriation. Third, the usage rate of the common pool resource impacts its availability in future periods. Fourth, each combatant allocates it scaptive resources between conflict and production in order to optimize current period wealth. ${ }^{9}$ Last, conflict results in a deterministic split of the contested wealth among the two rival groups.

Since the focus of this paper is to compare and contrast system behavior under the win and share approaches, our win approach adopts all of the above assumptions, except the last one. In our win model, the determination of the winner and loser is probabilistic. The winner takes all of the conflict spoils, and the loser gets nothing. This seemingly small difference leads to fundamental differences in the dynamic behavior the two models.

\footnotetext{
${ }^{8}$ Brito and Intriligator (1985) develop a two period game theoretic model of the circumstances leading to war. This model is static, however, as the two period game is played only once. In Usher's (1989) model, society moves between anarchy and despotism. However, this paper does not provide a specific solution for the transition between these two states. Powell (1993) models conflict between two states. In this repeated game, the actors do not interact, and there are no equations of motion. Alternating, each period, one state or the other decides on military spending, and in the next period on whether to attack.

${ }^{9}$ The maximization of current wealth is shared by virtually all the Hirshleifer-based conflict models due to the state of anarchy which prevails.
} 


\section{Modeling the win and share approaches to conflict}

The win and share models feature two actors, but the setup could be readily adapted to include more actors. Depending on the application, the actors may be thought of as individuals or groups. Each period, the two actors undertake productive activities that generate wealth. The wealth of each actor is open to appropriation by its rival. Actors allocate their resources between productive and conflictive (appropriative) activities. In general, the conflictive activities may combine both offensive and defensive activities. We ignore the potentially destructive effects of conflict. This assumption also allows us to compare our results to the existing literature, which uniformly ignores these destructive effects.

In the initial period, the actors are endowed with captive resource stocks that can embody human or physical capital. In subsequent periods, they convert conflict spoils into captive resources. Actor $i$ 's time $t$ captive resource stock is denoted by $N_{i t}$. Each period, the actors allocate their captive resource stocks between productive activities, $E_{i t}$, and conflictive activities, $F_{i t}$.

$$
N_{i t}=E_{i t}+F_{i t} ; i=\{1,2\}
$$

The portion of the captive stock devoted to productive activities by actor $i, N_{i t}$, is combined with the disputed resource, $S_{t}$, in order to generate wealth $H_{i t}$. Thus,

$$
H_{i t}=H\left(S_{t}, E_{i t}\right) ; i=\{1,2\} \text {, }
$$

where $H$ denotes the wealth production function with properties $H_{S}>0, H_{S S} \leq 0, H_{E}>$ $0, H_{E E} \leq 0$ and $H_{S E}>0 .{ }^{10}$ In the application presented in the next section, $S_{t}$ will represent natural resources, and $H_{i t}$ will represent actor $i^{\prime} s$ harvest. Other interpretations can also be posited. For example, in a political context, $S_{t}$ could represent the total number of potential voters, which are transformed into voters for party $i\left(H_{i t}\right)$ after being influenced by the party's campaign efforts $\left(E_{i t}\right)$. These efforts can be interpreted as efforts devoted towards developing a persuasive campaign platform or as monetary expenditures on media advertising. In a business context, one could view $H_{i t}$ as profits. These profits arise from combining the company's productive resources $\left(E_{i t}\right)$ with the pool of potential customers $\left(S_{t}\right)$.

Studies of conflict based on the Hirshleifer framework typically assume, as we do, that

\footnotetext{
${ }^{10}$ In a more general model one could assume that each actor has access to a different wealth generation technology. Our focus in this paper is to highlight the role of different approaches to the modeling of conflict, however, and this focus is best served by assuming that the actors have access to identical technologies.
} 
the total wealth the actors produce in period $t$,

$$
H_{t}=H_{i t}+H_{j t} \quad i, j=\{1,2\}, i \neq j
$$

is at stake. ${ }^{11}$ The actors derive income from the total yield of their productive activities $\left(H_{t}\right)$ by fighting over it. ${ }^{12}$ Actor $i$ 's period $t$ income, $Y_{i t}$, is the portion, $P_{i t}$, of the total income that actor $i$ obtains from the conflict process:

$$
Y_{i t}=P_{i t} H_{t} \quad i=\{1,2\}
$$

In the conflict literature, $P_{i t}$ is referred to as actor $i$ 's contest success function.

At this point that the win and share models begin to diverge. Under the share approach, ceteris paribus, the portion of wealth won by actor $i$ rises in the level of captive resources it devotes towards conflict, and falls in the level of captive resources its rival devotes towards conflict. That is,

$$
P_{i t}=p\left(F_{i t}, F_{j t}\right) \quad i, j=\{1,2\}, i \neq j
$$

where $p_{F_{i t}}>0$ and $p_{F_{j t}}<0$. Under the win approach, $P_{i t}$ is a random draw of 1 or 0 from a binomial distribution with probability of success parameter equal to $p\left(F_{i t}, F_{j t}\right)$. If $P_{i t}$ is 1 , actor $i$ wins all of the disputed wealth in period $t$. If $P_{i t}$ is 0 , all the conflict spoils go to actor $j$.

In a one-shot game, the actors'optimal allocations of efforts to production and conflict are the same regardless of whether the share or win interpretations of (5) are used, since both approaches lead to the same expected wealth. However, in a dynamic game, the conflict allocations will affect the behaviors of the actors in future periods since the realized levels of wealth will differ under the two approaches. This, in turn, will lead to differences in system dynamics between the two approaches.

In each period $t$, the actors allocate their captive resources $\left(N_{j t}\right)$ between productive $\left(E_{j t}\right)$ and conflictive activities $\left(F_{j t}\right)$, in order to maximize the expected period $t$ wealth. Expression (6) states the optimization problems facing actors $i$ and $j$.

$$
\max _{F_{i t}} p_{i}\left(F_{i t}, F_{j t}\right)\left[H_{i t}+H_{j t}\right] \quad \text { s.t. } \quad N_{i t}=E_{i t}+F_{i t} \quad i, j=\{1,2\}, i \neq j .
$$

\footnotetext{
${ }^{11}$ The assumption that the total generated wealth and not the disputed resource stock is open to appropriation, is one of modelling convenience. An equivalent approach would be to model groups as allocating their efforts to capturing and defending a portion of the disputed resource stock, and consuming all the generated wealth from that portion of the stock.

${ }^{12}$ It is not necessary to assume that the total generated wealth is disputed. However, assuming that only a portion of wealth is disputed would add little insight and will complicate the notation.
} 
Using (1) and (2) we can rewrite (6) as

$$
\max _{F_{i t}} p_{i}\left(F_{i t}, F_{j t}\right)\left[H\left(S_{t}, N_{i t}-F_{i t}\right)+H\left(S_{t}, N_{j t}-F_{j t}\right)\right] \quad i, j=\{1,2\}, i \neq j .
$$

In solving (7), we assume that the conflict resources are chosen simultaneously and that each actor holds Nash conjectures with regard to the level of captive resources its rival devotes to conflict. We assume also that the disputed and captive resource levels are common knowledge. Under these assumptions, optimization by each actor yields the following best response functions:

$$
\tilde{F}_{i t}=\tilde{F}_{i}\left(S_{t}, N_{i t}, N_{j t}, F_{j t}\right) \quad i, j=\{1,2\}, i \neq j .
$$

Using (8) to solve for the Nash equilibrium levels of allocations to conflict, we see that

$$
F_{i t}^{*}=F_{i}^{*}\left(S_{t}, N_{i t}, N_{j t}\right) \quad i, j=\{1,2\}, i \neq j .
$$

The expressions in (9) illustrate that the allocations to conflict each period depend only on the stocks of the disputed and captive resources. Combining (9) with (1), we see that the equilibrium levels of each actor's allocation of productive resources, $E_{i t}$, is also a function of $S_{t}, N_{i t}$, and $N_{j t}$ only. As such, the per period conflict and productive effort levels, as well as the total production of wealth, depend on the per period levels of the disputed and captive resource stocks.

We turn now to the dynamics. The growth rate of the disputed resource is assumed to be affected by its underlying growth rate $s\left(S_{t}\right)$ and the productive activities of the two actors. In the next section, $S_{t}$ represents the stock of a natural resource at time $t$, and the harvesting activities, $H_{t}$, of each actor deplete the resource. If instead we think of $S_{t}$ as the stock of potential customers in time $t, H_{t}$ could represent the sum of each firm's sales of a durable good, thus having a depleting effect on the number of potential customers. Similarly, political campaigns aimed at attracting elder voters might alienate younger persons, negatively impacting the total number of persons who might consider voting in future elections. As noted above, the period $t$ Nash equilibrium levels of captive resources devoted to productive activities depend only on the disputed and captive resources. Therefore, the growth rate of the disputed resource is given by

$$
\frac{d S_{t}}{d t}=s\left(S_{t}\right)-\mathcal{H}\left(S_{t}, N_{i t}, N_{j t}\right) \quad i, j=\{1,2\}, i \neq j .
$$

where $s$ is the intrinsic growth rate of the resource stock and $\mathcal{H}$ is generated wealth. 
We assume that the growth rates of captive resources are positive functions of each actor's current captive resources and income. That is,

$$
\frac{d N_{i t}}{d t}=n_{i}\left(N_{i t}, Y_{i t}\right) . \quad i=\{1,2\}
$$

where $n_{N_{i t}}>0$ and $n_{Y_{i t}}>0$. We also assume that $\left.\frac{d N_{i t}}{d t}\right|_{Y_{i t}=0}<0$, which implies that if actor $i$ 's income is zero each period, the actor's captive resources will eventually decline to zero. For example, successful firms can invest profits for future contests, while successful political parties and candidates often find it easier to raise funds. However, unsuccessful firms and parties often fold. Using (4), (5) and (9) we write each actor's current income as

$$
Y_{i t}=Y_{i}\left(S_{t}, N_{i t}, N_{j t}\right) \quad i, j=\{1,2\}, i \neq j
$$

The evolution of the system over time is described by (10), (11), and (12). The tensions in the model are now clear. From (11), we see that future captive resources are rising in current income and resources. But (10) illustrates that the income generation process diminishes the amount of the disputed resource available for the generation of wealth in the future. While these tensions occur under both the win and share approaches, the fact that (12) subsumes (5) suggests that $Y_{i t}$ will differ under the two approaches, leading to differences in system dynamics. Investigating the nature of these differences requires the use of specific functional forms for the contest success function, $p\left(F_{i t}, F_{j t}\right)$, the productive activity function, $H\left(S_{t}, E_{i t}\right)$, the disputed resource dynamics, $d S_{t} / d t$, and the captive resource dynamics, $d N_{i t} / d t$. To simplify the notation, from here on we drop the time subscripts.

\section{An application: Conflict over renewable resources}

This section applies our win and share approaches to a case of conflict over natural resources. The actors are groups of people, and the captive resources are the populations (and the human capital they embody). Groups combine the captive resources with the natural resource to produce income by harvesting. This income - the disputed resource - is subject to appropriation by the rival group. Groups can raise their wealth by either harvesting or appropriating each other's harvests. Each group transforms its income into captive resource via procreation, where fertility rises in income. Thus, a predetor pray relationship exists between population (the predator) and the resource (the pray). 


\subsection{The share approach}

Under the share approach we adopt the most common contest success function in the literature, which was suggested by Tolluck (1980):

$$
P_{i}=\frac{\alpha_{i} F_{i}}{\alpha_{1} F_{1}+\alpha_{2} F_{2}} \quad i=\{1,2\}
$$

where $\alpha_{1}$ and $\alpha_{2}$ are fighting efficiency parameters, capturing attributes such as quality of fighers and leadership, conflict infrastructure, and resolve. ${ }^{13}$

The harvesting technology of each group is modeled as:

$$
H_{i}=\beta S E_{i} \quad i=\{1,2\}
$$

where $\beta$ denotes harvesting efficiency. ${ }^{14}$

Substituting (13) and (14) into (6), the optimization problem facing actor $i$ is

$$
\max _{F_{i t}} \frac{\alpha_{i} F_{i}}{\alpha_{1} F_{1}+\alpha_{2} F_{2}}\left[\beta S E_{1}+\beta S E_{2}\right] \quad \text { s.t. } \quad N_{i t}=E_{i t}+F_{i t} \quad i, j=\{1,2\}, i \neq j . .
$$

Solving (15) yields the reaction functions for groups 1 and 2, respectively:

$$
\frac{F_{1}}{F_{2}}=\frac{\alpha_{2}\left(E_{1}+E_{2}\right)}{\alpha_{1} F_{1}+\alpha_{2} F_{2}}
$$

and

$$
\frac{F_{2}}{F_{1}}=\frac{\alpha_{1}\left(E_{1}+E_{2}\right)}{\alpha_{1} F_{1}+\alpha_{2} F_{2}}
$$

Solving (16) and (17) for $F_{1}$ and $F_{2}$, we obtain the following Nash solutions:

$$
F_{1}=\frac{\sqrt{\alpha_{2}}\left(N_{1}+N_{2}\right)}{2\left(\sqrt{\alpha_{1}}+\sqrt{\alpha_{2}}\right)} \quad \text { and } \quad F_{2}=\frac{\sqrt{\alpha_{1}}\left(N_{1}+N_{2}\right)}{2\left(\sqrt{\alpha_{1}}+\sqrt{\alpha_{2}}\right)} .
$$

\footnotetext{
${ }^{13} \mathrm{~A}$ more general contest success function is $P_{i}=\left(\alpha_{i} F_{i}^{m}\right) /\left(\alpha_{1} F_{1}^{m}+\alpha_{2} F_{2}^{m}\right)$, where $m$ is a parameter that measures the effectiveness of fighting. As noted by Skaperdas (1996) and Garfinkel and Skaperdas (2000), many studies set $m=1$, as we do here. One could compare the share and win approaches using the more general contest success function. This would require solving the resulting reaction functions numerically for the conflict allocations each period, a task which we defer to future research.

${ }^{14}$ This technology is popular in the resource literature (e.g., Clark, 1990: Chapter 1; Brander and Taylor, 1998). Expression (14) assumes that each group's harvest does not depend on the harvest of the rival group. This assumption is likely to hold when the resource is abundant. When the resource is scarce each group's harvest may impose a negative externality on its rival's harvest, thereby reducing the marginal return to harvesting. The reader may note, however, that the marginal return to harvesting in (14), $\beta S$, falls as the resource stock declines.
} 
Note that at this interior solution, the fighting resources are determined by the overall level of captive resource, $N_{1}+N_{2}$. Consequently, the optimal conflict allocation may exceed the level of total captive resources available for the resource-poor group. ${ }^{15}$ We refer to this situation as cornering, and say that group $i$ is cornered.

When one group is cornered, equation (18) does not hold. Assuming group $i$ is cornered, the equilibrium allocations of fighting resources will be

$$
F_{i}=N_{i} \quad \text { and } \quad F_{j}=-\frac{\left(\alpha_{i} N_{i}-\sqrt{\left(\alpha_{i} N_{i}\left(\alpha_{i} N_{i}+\alpha_{j} N j\right)\right)}\right)}{\alpha_{j}} \quad i, j=\{1,2\}, i \neq j .
$$

The conflict allocations in (19) also are Nash solutions. That is, neither actor can benefit by deviating from its allocation decision in (19) given the decision of its counterpart. ${ }^{16}$

Under the share approach, cornering in this application can occur only if the initial disparity of the populations is set exogenously high enough. Even in this case, as long as the conditions ensuring an interior steady state equilibrium exist, the share model self-corrects: in steady state, the two groups will have the same population, and as the groups approach steady state, neither will be cornered. ${ }^{17}$ As shown in the next sub-section, under the win approach, cornering can occur endogenously even when there is no disparity in the groups' initial captive resource stocks.

Next we determine the total harvest (the contested wealth). Using (1), (14) and (18), we see that at the interior equilibrium the total harvest is:

$$
H=H_{1}+H_{2}=S \beta\left(\frac{N_{1}+N_{2}}{2}\right) .
$$

If group $i$ is cornered, it does not allocate any resources to productive activities, and the total harvest is

$$
H=S \beta\left(N_{j}-F_{j}\right)=S \beta\left(N_{j}+\frac{\left(\alpha_{i} N_{i}-\sqrt{\left(\alpha_{i} N_{i}\left(\alpha_{i} N_{i}+\alpha_{j} N_{j}\right)\right)}\right)}{\alpha_{j}}\right)
$$

The income from conflict for each group is given by:

$$
Y_{i}=\frac{\alpha_{i} F_{i}}{\alpha_{1} F_{1}+\alpha_{2} F_{2}} H \quad i=\{1,2\}
$$

\footnotetext{
${ }^{15}$ When we label a group resource-rich or resource-poor, we are refering to its relative level of captive resources.

${ }^{16}$ Only one group can be cornered in any given period. To see that, assume, for example, $\alpha_{1}=\alpha_{2}=1$. If group 1 is in the corner, (18) implies that $F_{1}=\frac{N_{1}+N_{2}}{4}>N_{1}$. Hence, $N_{2}>3 N_{1}$. In this case, it must be that $F_{2}=\frac{N_{1}+N_{2}}{4}<N_{2}$, or group 2 is not cornered.

${ }^{17}$ See Maxwell and Reveny (2004) for a detailed discussion of this result.
} 
At the interior equilibrium, we substitute (20) and (18) into (22), which gives the Nash equilibrium income levels in each period:

$$
Y_{i}=\frac{\sqrt{\alpha_{i}}}{\left(\sqrt{\alpha_{i}}+\sqrt{\alpha_{j}}\right)} S \beta \frac{\left(N_{i}+N_{j}\right)}{2} \quad i, j=\{1,2\} \quad i \neq j
$$

If group $i$ is cornered, we substitute (21) and (19) to find the Nash equilibrium income:

$$
Y_{i}=\frac{\alpha_{i} N_{i} S \beta}{\alpha_{i} N_{i}+\alpha_{j}\left(-\frac{\left(\alpha_{i} N_{i}-\sqrt{\left(\alpha_{i} N_{i}\left(\alpha_{i} N_{i}+\alpha_{j} N j\right)\right)}\right)}{\alpha_{j}}\right)}\left(N_{j}+\frac{\left(\alpha_{i} N_{i}-\sqrt{\left(\alpha_{i} N_{i}\left(\alpha_{i} N_{i}+\alpha_{j} N_{j}\right)\right)}\right)}{\alpha_{j}}\right)
$$

and

$$
Y_{j}=\frac{\alpha_{j}\left(-\frac{\left(\alpha_{i} N_{i}-\sqrt{\left(\alpha_{i} N_{i}\left(\alpha_{i} N_{i}+\alpha_{j} N j\right)\right)}\right)}{\alpha_{j}}\right) S \beta}{\alpha_{i} N_{i}+\alpha_{j}\left(-\frac{\left(\alpha_{i} N_{i}-\sqrt{\left(\alpha_{i} N_{i}\left(\alpha_{i} N_{i}+\alpha_{j} N j\right)\right)}\right)}{\alpha_{j}}\right)}\left(N_{j}+\frac{\left(\alpha_{i} N_{i}-\sqrt{\left(\alpha_{i} N_{i}\left(\alpha_{i} N_{i}+\alpha_{j} N_{j}\right)\right)}\right)}{\alpha_{j}}\right) .
$$

We now turn to the model's dynamics. The populations of each group are assumed to evolve according to the following equations of motion:

$$
\frac{d N_{i}}{d t}=N_{i}\left(\varepsilon+\phi \frac{Y_{i}}{N_{i}}\right) \quad i=\{1,2\}
$$

where $\varepsilon$ is the natural net birth rate (difference between natural birth and mortality rates), which is assumed to be negative, and the term $\phi \frac{Y_{i}}{N_{i}}$ represents dependence of fertility on the per capita income $(\phi>0) .{ }^{18}$ Since we adopt the convention that $\varepsilon$ is negative, population will decline to zero for sufficiently low rates of fertility.

We assume that the natural growth of the resource $s\left(S_{t}\right)$ is given by the logistic growth function. Substituting the logistic resource growth function in (10) gives the following equation of motion:

$$
\frac{d S}{d t}=\left[r S\left(1-\frac{S}{K}\right)\right]-H
$$

\footnotetext{
${ }^{18}$ While appropriate for underdeveloped societies, the assumption of $\phi>0$ may not describe developed countries, where fertility seems to decline with the resource harvest or the income it represents. However, conflict over resources is clearly more applicable to underdeveloped societies. Another interpretation of the term $\phi \frac{Y_{i}}{N_{i}}$ may be that the resource harvest (e.g., food, water) is essential for procreation. Note also that one could assume that $\varepsilon$ and $\phi$ differ across groups. This would complicate the analysis without adding much insight.
} 
where, the parameter $r$ is the intrinsic growth rate of the resource, $K$ is the resource carrying capacity, and $H$ is given by (20) or (21), depending on whether group $i$ is cornered or not. ${ }^{19}$

If one of the groups, say $j$, dies, it is assumed that the remaining group $i$ allocates all of its resources to harvesting, and consumes its entire harvest each period. ${ }^{20}$ In this case, the evolution of the system in all subsequent periods following the death of one group is given by

$$
\frac{d N_{i}}{d t}=N_{i}(\varepsilon+\phi S \beta) \quad \text { and } \quad \frac{d S}{d t}=r S\left(1+\frac{S}{K}\right)-S \beta N_{i}
$$

This system also is solved numerically one step. After finding $N_{i t+1}$ and $S_{t+1}$, we check to see that the population of group $i$ exceeds 2. If it does, we solve system (28) again. If it does not, we solve the single differential equation $d S / d t=r S(1+S / K)$ under which the resource stock will eventually reach its carrying capacity, $K$.

\subsection{The win approach}

Under the win approach, conflict represents a Bernoulli trial with success probability $p_{i}$. Group $i$ wins the conflict if the trial results in a success, while group $j$ wins if the trial results in a failure. The victorious group gets the total harvest, and the defeated group gets nothing.

For the contest success function in (13), the probability that group $i$ wins the conflict is given by:

$$
\operatorname{Pr}(\text { group } i \text { wins })=\frac{\alpha_{i} F_{i}}{\alpha_{1} F_{1}+\alpha_{2} F_{2}}
$$

Each group decides how to allocate its captive resources between production and fighting, in order to maximize its expected payoff. This problem is similar to (15), which is solved under the share approach. Ex ante, the groups maximize their expected payoffs from conflict. Thus their allocation decisions under both approaches are given by (18), ceteris paribus.

Substituting (18) into (29), we can see the POP at work under the win approach. As long as no group is cornered, each group, whether resource rich or poor, faces the same probability

\footnotetext{
${ }^{19}$ The logistic resource growth function is used in many studies, including Clark (1990), Brander and Taylor (1998), Reuveny and Maxwell (2001), and Maxwell and Reuveny (2004).

${ }^{20}$ One might assume that in the absence of conflict the surviving group will follow one of several other strategies. For example, it may devise some optimal harvesting plan over time. This is not central to our paper, which focuses on conflict, and would not affect any of the results we discuss below.
} 
of victory. The POP stabilizes the system by breaking a one to one correspondence between relative resource levels and the probability of victory. ${ }^{21}$

Next, we award the total harvest to group $i$ according to:

$$
\begin{aligned}
& P_{1}= \begin{cases}1 & \text { if } \frac{\alpha_{1} F_{1}}{\alpha_{1} F_{1}+\alpha_{2} F_{2}}<\nu \\
0 & \text { otherwise }\end{cases} \\
& P_{2}=1-P_{1}
\end{aligned}
$$

where $\nu$ is drawn at random from the uniform distribution over the interval $[0,1]$. If $P_{i}$ is one, actor $i$ wins all of the disputed wealth. If $P_{i}$ is zero, actor $j$ wins all of the conflict spoils.

If no group is cornered, $P_{i}$ is determined by substituting (18) into (30). If group $i$ is cornered, $P_{i}$ is determined by substituting (19) into (30). In each case, it is the fog of war that may play a substantial role. While it is apparent that the cornered group faces a lower probability of victory than its rival, the fog of war (operationalized as the random draw $\nu$ ) ensures that this probability is never zero. Thus a victory that would allow the resource poor group to emerge from the corner is possible. The harvest open for appropriation under the win approach is given by (20), without cornering, and by (21), when group $i$ is cornered. Once the conflict spoils have been determined, we can describe evolution of the system along one the following cases.

\section{Case 1: Neither group is cornered, group $i$ is the winner}

Group $i$ gets income $Y_{i}=S \beta\left(\frac{N_{i}+N_{j}}{2}\right)$, while group $j$ receives no income. Thus, the evolution of the system is given by:

$$
\begin{aligned}
\frac{d N_{i}}{d t} & =N_{i}\left(\varepsilon+\phi S \beta\left(\frac{N_{i}+N_{j}}{2 N_{i}}\right)\right) \\
\frac{d N_{j}}{d t} & =N_{j t} \varepsilon \\
\frac{d S}{d t} & =r S\left(1-\frac{S}{K}\right)-\beta S\left(\frac{N_{i}+N_{j}}{2}\right) \quad i, j=\{1,2\}, i \neq j .
\end{aligned}
$$

\section{Case 2: Group $i$ is cornered, group $i$ the winner}

\footnotetext{
${ }^{21} \mathrm{Had}$ such a correspondence been present in the model, it would have lead to more instances of a stronger player dominating, and eventually killing off its opponent.
} 
Although group $i$ is the weaker of the two groups, it nonetheless prevails in the battle. Consequently, it receives income $Y_{i}=S \beta\left(N_{j}+\frac{\left(\alpha_{i} N_{i t}-\sqrt{\left(\alpha_{i} N_{i t}\left(\alpha_{i} N_{i t}+\alpha_{j} N_{j t}\right)\right)}\right)}{\alpha_{j}}\right)$, while group j receives no income. Thus, the evolution of the system is given by:

$$
\begin{aligned}
\frac{d N_{i}}{d t} & =N_{i}\left(\varepsilon+\frac{\phi S \beta}{N_{i}}\left(N_{j}+\frac{\left(\alpha_{i} N_{i}-\sqrt{\left(\alpha_{i} N_{i}\left(\alpha_{i} N_{i}+\alpha_{j} N_{j}\right)\right)}\right)}{\alpha_{j}}\right)\right), \\
\frac{d N_{j}}{d t} & =N_{j} \varepsilon \\
\frac{d S}{d t} & =r S\left(1-\frac{S}{K}\right)-\beta S\left(N_{j}+\frac{\left(\alpha_{i} N_{i}-\sqrt{\left(\alpha_{i} N_{i}\left(\alpha_{i} N_{i}+\alpha_{j} N_{j}\right)\right)}\right)}{\alpha_{j}}\right) \quad i, j=\{1,2\}, i \neq j .
\end{aligned}
$$

\section{Case 3 Group $i$ is cornered, group $j$ is the winner}

Group $j$ receives $Y_{j}=S \beta\left(N_{j}+\frac{\left(\alpha_{i} N_{i}-\sqrt{\left(\alpha_{i} N_{i}\left(\alpha_{i} N_{i}+\alpha_{j} N_{j}\right)\right)}\right)}{\alpha_{j}}\right)$, while group $i$ receives no income. Thus the evolution of the system is given by:

$$
\begin{aligned}
& \frac{d N_{i}}{d t}=N_{i} \varepsilon \\
& \frac{d N_{j}}{d t}=N_{j}\left(\varepsilon+\frac{\phi S \beta}{N_{j}}\left(N_{j}+\frac{\left(\alpha_{i} N_{i}-\sqrt{\left(\alpha_{i} N_{i}\left(\alpha_{i} N_{i}+\alpha_{j} N_{j}\right)\right)}\right)}{\alpha_{j}}\right)\right) \\
& \frac{d S}{d t}=r S\left(1-\frac{S}{K}\right)-\beta S\left(N_{j}+\frac{\left(\alpha_{i} N_{i}-\sqrt{\left(\alpha_{i} N_{i}\left(\alpha_{i} N_{i}+\alpha_{j} N_{j}\right)\right)}\right)}{\alpha_{j}}\right) \quad i, j=\{1,2\}, i \neq j .
\end{aligned}
$$

Note that these three cases describe 6 possible outcomes since, for any specific case, the identity of group $i$ may be either group 1 or group 2 . All of these dynamic systems are nonlinear. Consequently, there is no analytical solution to the dynamic evolution of the system. However, it is possible to employ numerical methods to determine the dynamics. At each point in time, we solve numerically one of the six systems defined above, depending on the particular situation, moving the relevant system one period ahead in time to obtain $N_{1_{t+1}}, N_{2_{t+1}}$, and $S_{t+1}$.

A group is said to be dead if its population falls below 2 . Since $\varepsilon<0$, a group will die if losses occur with sufficient frequency, since they result in zero income. Under the win 
approach, death can occur endogenously a result of a series of lost battles. Accordingly, at each iteration of the system, we check to see that no group has died. If no group has died, we use $N_{1_{t+1}}, N_{2_{t+1}}$, and $S_{t+1}$ in the determination of each group's optimal captive resource allocation to conflict via (18) and (19), where the outcome of conflict is determined by (30). The results are fed into one of the above six systems of differential equations, according to the particular situation, and this process is repeated.

The presentation here comes close to overstating the complexity of the share approach. Cornering occurs under the share approach if the initial populations of the two groups differ by a large enough margin, or the fighting efficiencies $(\alpha)$ are widely divergent. In the case where the initial populations differ but the groups are parametrically symmetric, once one group emerges from being cornered neither group will ever be cornered again. Thus, absent a large initial resource imbalance, the evolution of the system under the share approach is fully characterized by (26) and (27).

Like the share approach, the win approach to conflict also can generate death. In the share approach, this occurs but only if the initial conditions for the population are such that one group is much larger than its combatant, the carrying capacity or initial resource stock are too small to support the total population, the resource intrinsic growth rate is too low, or the harvesting efficiency is too high. The win approach to conflict can generate death endogenously, under the very same parameters for which the share approach generates interior trajectories, depending on the outcome from the random element of the system. When death of one group occurs, the remaining group and the resource evolve under the same equations of motion as in the share approach.

It is evident that the evolution of the system under the win approach is more complex than the one under the share approach. In the next section, we shall see that the analytical differences between the two approaches result in considerable practical differences that, taken in sum, imply that the share approach is a poor predictor of conflict based on a winner-takeall system.

\section{Results}

In this section, we examine the dynamic behavior of the model under the win and share approaches. Two methods may be used in such cases to study system's dynamics: local stability analysis and numerical simulations. A local stability analysis involves linearizing the system around the steady state(s) and finding the eigen values. This method is not 
applicable in our case since the system's equations can change from period to period, due to its stochastic nature. Consequently, we need to investigate the dynamics via numerical simulations.

In order to simulate the systems, we must parameterize them. There are, of course, many sets of parameters from which one could choose. In the simulations we discuss below the paramater set is based on Reuveny and Maxwell (2001). ${ }^{22}$ Our conflict efficiency parameters, $\alpha_{1}$ and $\alpha_{2}$, are set to 1 , and the two initial populations are set to 40 . The initial resource stock, and its carrying capacity $K$, are both set to 12,000 . The resource growth rate, $r$, is set to 0.04 , the natural net birth rate of the population, $\varepsilon$, is set to -0.1 . The population fertility parameter, $\phi$, is set to 4 , and the harvesting efficiency parameter, $\beta$, is set to 0.00001 .

In presenting the results, the term "run" refers to a single trajectory of the system. For a given set of parameters and initial conditions, the share approach generates a unique trajectory. The stochastic aspect of conflict under the win approach means that trajectories from repeated runs will generally differ even for the same set of parameters and initial conditions. Thus, we examine both system behavior of a single run and the average behavior of the system.

\subsection{Single run behavior}

Figure 1 presents the population trajectories of groups 1 and 2 from a single run under the win approach, and of group 1 under the share approach. ${ }^{23}$ While our application focuses on conflict over natural resources, we believe the flavor of the dynamic behaviors generated under the win approach mimics several observed behaviors of repeated conflicts in the real world.

The main differences between the two approaches can be seen via their population trajectories. Figure 1 presents the population trajectories of under each approach. The two population trajectories arising under the win approach are from a single, completely interior, run where neither group is cornered or dies. This run is the one that is most likely to

\footnotetext{
${ }^{22}$ Reuveny and Maxwell (2001) use the population and resource paramters from Brander and Taylor (1998), and the conflict parameters from Hirshleifer (1988). Brander and Taylor choose the resource and population parameters so as to roughly mimic estimated information about historical Easter Island in a model without conflict. Reuveny and Maxwell (2001) cite studies arguing that Easter Island exhibited conflict over resources. This story provides but one example of historical societies that fought over natural resources. In recent decades, there have been many conflicts of this type in developing countries (Homer-Dixon, 1999; Maxwell and Reuveny, 2000).

${ }^{23}$ Group 2's trajectory under the share approach is exactly the same as group 1's trajectory, since the two groups have identical parameters and initial conditions.
} 
resemble that under the share approach, which is unique for the given set of parameters and intial conditions.

[Insert Figure 1 here: Populations from a Single Run]

In Figure 1, the population trajectories under both approaches are cyclical. This is due to the underlying predator-prey nature of the application studied here. That said, there are many differences between the two trajectories. First, the trajectory obtained under the share approach is smooth. While the trajectories obtained under the win approach are volatile, this reflects the two distinguishing features of the latter approach, namely the fog of war, and the winner-take-all characteristic. Volatility is a common feature of many real-world conflicts. In the business world, for example, winning a large client is rewarded with a rise in the winner's stock price, while a loser's stock price will suffer a decline, contributing to the volatility reflected in stock prices. In the military context, although warrning campaigns may not lead to decisive outcomes in the long run, individual battles are typically won or lost, making campaigns volatile.

Second, while the share trajectories for each group are identical, the win trajectories differ between the two groups, despite their identical paramter values and initial conditions. Unlike the share approach, endogenous heterogeneity typically arises under the win approach. This is a realistic aspect of conflict. In fact, it is highly unlikely that combatants that either begin with identical resources, or that face each other mid-conflict with identical resources, will always earn equal an equal share of the conflict spoils and follow the same resulting trajectory, as the share approach predicts.

Third, under the win approach, both populations grow faster and reach higher peaks than they do under the share approach. This occurs because the population gains due to a victory more than offset the population declines due to a loss. This phenomenon will arise whenever the winner can generate positive returns from investing the spoils of conflict. This is often the case in a business context since companies strive to achieve positive internal growth rates. In a military setting as well, some victories can lead to capture of strategic territories from which larger attacks can be launched.

Fourth, under the win approach the relative population dominance of the two groups changes over time. In Figure 1, the relative position of the two groups changes over 15 times. Even if a group is dominant, it can still lose a battle, allowing its rival to recover and potentially gain dominance in subsequent engagements. The fact that the relative dominance 
of the two groups changes frequently reflects the Paradox of Power. One might expect a dominant group to quickly drive its opponent into submission. The POP, however, limits the dominance of the more powerful group allowing weaker groups to survive, and possibly thrive. Changes in the relative dominance of combatants is common in virtually all forms of conflict. Political parties generally hold power for finite intervals. The rise and fall of great military and economic powers has been common throughout history. The long term dominance of a single firm in any particular industry is rare. We see from equation (18) that the two groups allocate the same amount of effort to fighting regardless of their individual resource levels. The weaker group allocates relatively more of its resources to fighting, resulting in an equal probaility of victory for each group (equation (30)), hence a paradox of power.

As can be obeserved from Figure 1, had we plotted the total populations under the two approaces, we would have seen that the win population reaches a greater peak than the share approach, and does so earlier. Consequently, the resource comes under greater pressure earlier and the predator-prey aspect of the model has a larger impact. Under the win approach, the decline in population is quicker and larger than under the share approach. The resource stock declines faster under the win approach than under the share approach, and then recovers faster once the win population falls below the share population. The number of fighters also is higher under the win approach than under the share approach, as long as the win population is larger than the share population.

Figure 1 does not exhibit cornering. Recall that when a group is cornered, it devotes all of its resources (in this case population) to conflict. The cornered group faces a lower probability of victory than the non-cornered group, but it can still win battles, since victory also has a stochastic component. This possibility gives rise to the dynamics shown in Figures 2 and 3. In Figure 2, group 2 emerges from being cornered early on in the run, but later suffers several defeats that return it to the relatively weak position of being cornered. Figure 3 illustrates a run that results in the eventual extinction of group 2, following which the population of group 1 recovers.

[Insert Figure 2 here: Cornering from a Single Run] [Insert Figure 3 here: Death from a Single Run]

Figure 2 shows the important influence of the fog of war on the stability of the conflict system. A cornered group, although out-numbered in terms of fighting resources by its 
stronger rival, can emerge victorious. If conflict outcomes did not exhibit this random component, cornering would be followed inevitably by the death of the weaker group.

Figure 2 captures another important aspect of real world conflict. The length of time a weaker group is cornered is shorter at the beginning of the trajectory than at the end. This happens because the beginning of the trajectory features a larger resource stock. As such, a victory by the cornered actor is rewarded by a high rate of population growth, allowing it to quickly emerge from the corner. Later on in the trajectory, population grwoth rates are lower. As a result, victories impact less the population of the winning group in subsequent periods. In this case, a victory by the weaker group may not allow it to emerge from the corner in the next period. This translates into longer spells of the weaker group being cornered.

These features are seen in many real world conflicts. In a business context, we can map these outcomes to markets that experience higher or lower levels of growth. In higher growth industries, we see more volatility and instances where companies must fully mobilize their resources. At the same time, there are more growth opportunities, allowing once weak firms to gain dominant positions. In lower growth industries, we often see firms stuggling for considerable lengths of time before "turn-arounds" take place. In a military setting, victories occuring when infrastructures are in place can have large impacts on the relative strength of combatants. Victories occuring after infrastrcuture was destroyed by repeated conflict may have little impact beyond changing the locations of the front lines.

Figure 3 shows the possibility of the death of a combatant. Given the early volatility shown in Figure 2, one might expect death, if it occurs, to occur early on in the trajectory. While it is true that many deaths occur early on, Figure 3 illustrates that deaths also occur later in the trajectory.

Death in our model represents the breakdown of anarchy, a term coined by Hirshleifer (1995) to denote the nonexistance of an interior conflict equilibrium (in the game theoretic sense). While the term breakdown suggests a movement from a situation of conflict to a situation of no conflict, Hirshliefer's model does not generate this transition endogenously. Our model of repreated conflict under the win approach generates endogenously this transition. A small number of conflict losses early on, or a large number of losses later, can lead to a situation where one of the combatants can no longer engage in battle. Thus, the endogenous breakdown of anarcy. ${ }^{24}$

\footnotetext{
${ }^{24}$ This results from a series of losses that drives population below a single individual. Unable to reproduce, the group dies, and conflict ends.
} 
In the bussiness environment, the possibility of the breakdown of anarchy is applicable only when a particular market segement turns into a pure monopoly, following the collapse of rival firms. Such events are not observed frequenty due to anti-trust laws and competition regulations. In the war environment, the breakdown of anarchy is observed more freqently as battles often end with, for all practical purposes, the death of one side. Germany, for example, ceased being an important actor on the world stage of great powers following its loss in World War II, while its rivals, including the USSR, experienced relatively high growth for some time following the end of hostilities. ${ }^{25}$

Figures 1-3 illustrate that win-based conflict generates richer dynamics than share-based conflict. These dynamics capture many salient features of repeated real-world conflict, including a dominant group facing a greater probability of victory than a weak group, death of combatants that were once dominant, relative changes in balance of power of actors, and the rise of weaker groups. The most striking feature of these dynamics is not their randomness (one would expect some randomness due to the randomness introduced in the contest success function) but rather the pattern of randomness. Our trajectories exhibit remarkable persistence. These features are driven by the interplay between the Paradox of Power, which implicitly places limits on the power of the dominant group, and the Fog of War, which enables even a weak (cornered) group to emerge victorious. ${ }^{26}$

\subsection{Average behavior}

Under the win approach, particular runs depend on the realization of combat outcomes. In contrast, under the share approach a single run represents the unique behavior of the system, for a given parameterization and initial conditions. To study the general behavior of the system under the win approach, we present per-period point averages of the system's variables. It is important to note, however, that in doing so we do not want to downplay the importance of single run results. After all, history occurs only once.

Our goal in this section is to investigate whether the outcome of the share approach is a good predictor of the behavior of the win approach on average. This immediately raises the question of the number of runs necessary to adequately describe the "average" behavior of

\footnotetext{
${ }^{25}$ This example needs to be qualifed in that on December 11, 1941, Germany entered into conflict with another actor, the United States. Such exogenous shocks are not covered by the model. The later decline of the USSR in the absence of conflict with Germany, also is not captured, of course, in the model.

${ }^{26}$ That the interplay between the Paradox of Power and the Fog of War results in a remarkably stable system also is reflected in the fact that out of 2000 runs discussed in the next section, only 89 runs resulted in the death of either group.
} 
the system. To address this question, we developed the Monte Carlo procedure described in the Appendix, which consisted of simulating the system a number of times and calculating statistics aimed at capturing the degree of dispersion around the system't mean behavior. In each simulation, or run, we started with a different seed for the random number generator and generated different values of $\nu$ (in (30)), and ran the system for $\mathrm{N}$ periods. An average system trajectory is created, consisting of point averages. The results of our Monte Carlo procedure, presented in the Appendix, suggest that the use of 2000 runs captures the intrinsic mean tendency of the system under the win approach. Figures 4-6 are each based on 2000 runs.

In Figures 4-6, we compare the mean behavior of the system under the win approach with system behavior under the share approach. We present point averages for a thousand periods. This allows the system's variables under the share approach to reach their steady state levels. $^{27}$

In Figure 4, we present the point averages of group 1's population, and compare that behavior with group 1's population under the share approach. ${ }^{28}$ The figure illustrates several important differences between the two approaches. First, the cyclic behavior of the system under the win approach is more pronounced, with the population rising faster and reaching a higher level than under the share approach. Second, the volatility in group 1's average population is greater than that under the share approach. Finally, on average, the long run population level of group 1 under the win approach is greater than that under the share approach. That is, the differences observed from a single run in Figure 1 occur systematically.

[Insert Figure 4 here: Population Means]

Figures 5 and 6 present the average fighting allocations and resource trajectories. In Figure 5, the win conflict system is more volatile, and exhibits more intense fighting than the share conflict system (as measured by the allocation of people to conflict). The win approach also exhibits a lower natural resource stock in the long run, compared with the share appraoch. Winner take all competition then, intensifies the pressure on the system relative to the interaction in the system under the share approach.

\footnotetext{
${ }^{27}$ The figures graph the point averages based only on runs in which the populations of both groups survive for the 1000 periods (this was the case in over 95 percent of the 2000 runs).

${ }^{28}$ We do not present the mean behavior of group 2's population under either approach. As one should expect, it is virtually identical to the mean population trajectory of group 1 under the win approach, and is exactly identical under the share approach.
} 
[Insert Figure 5 here: Fighting Allocations Means]

[Insert Figure 6 here: Resource Means]

In sum, although the ex ante allocation decision of the rival groups take the same form under the two approaches, the share-based approach is not a good predictor of system dynamics under the win approach even on average.

\section{Conclusions}

This paper examines the dynamics of repeated conflict. We have developed a model of repeated, winner-take-all conflict that features two attributes observed in many real world conflicts: the Fog of War, and the Paradox of Power. We have labeled this the win approach to conflict and have compared it to a benchmark model that features a share approach to conflict. We have found that the two approaches lead to important differences in the behavior of agents, and that these behavioral differences lead to lasting differences in the behavior of the dynamic system.

Our results have important implications for the study of repeated conflict situations, which are common in military, political and economic interactions. The share-based approach to conflict is not a good predictor of system dynamics from the win approach, even on average. We find even greater differences between the two approaches in the outcomes of a single run. These findings are important because system behavior under the win-based conflict mimics many real life aspects of repeated conflict. The relative dominance of combatants can change over time. While dominant combatants face a greater likelihood of victory, weaker combatants can still win. The model also can give rise to a behavior that mimics the rise and fall of great powers. The victories of weak combatants can come at points in which defeats would lead to extinction. These victories can be turning points in relative dominance, and so can profoundly affect the system's overall behavior and thus, viewed from the final period, its history.

Our paper represents an initial investigation into the different approaches to dynamic conflict. As such, there are many avenues for future research. For example, the agents in our model are myopic. It would be worthwhile to examine the two approaches in a setting where agents are forward looking. The models developed here are complex, and there are potentially many interesting and relevant questions that could be investigated from comparative dynamic experiments on the attributes of the two approaches to conflict. 
For example, one could investigate the impact of differences across combatants including conflict efficiency, harvesting efficiency, and initial power heterogeneities. Another set of

questions can focus on the effect of parameters of the resource (e.g., carrying capacity), or the population (e.g., birth rate). We are currently addressing these questions in a series of companion papers.

\section{Appendix}

In order to determine how many runs are necessary to capture the mean tendency of the system under the win approach we conducted a Monte Carlo procedure, which was comprised of the following steps:

1. Initialize the seed of the random number generator that generates different values of $\nu$ (in (30)) each period.

2. Run the system $\mathrm{N}$ times from that seed, producing $\mathrm{N}$ runs, each lasting 1000 periods, generating trajectories for the populations and natural resource stocks.

3. Compute populations and resource stock averages for each period, across the $\mathrm{N}$ runs.

4. Repeat the process for four other seeds for the random number generator, generating in total 5 experiments.

5. Compute the maximum and average difference at each point in time, and compare them over the 5 experiments.

6. Perform this procedure for $\mathrm{N}=100,200,500,1000$, and 2000 , for each of the 5 experiments.

7. Compare the recorded statistics across the 5 experiments, and record the percentage differences in these statistics in Table 1.

The number at the top left corner in Table 1, 0.267, indicates that over the five experiments, each computed from 100 single runs based on the same seed used for the random draw in the model, the maximum difference between the average population of group 1 recorded for each of the 1000 periods was $26.7 \%$. The number below, 0.091 , indicates that on average the population of group 1 differed by about $9.1 \%$ at each point in time across the five experiments. The maximum and average difference for the population of group 2 is about $38 \%$ 
and $10 \%$ for group 2 , and about $38 \%$ and $3 \%$ for the resource stock. Thus, representing the mean behavior of the system based on 100 runs would not be very accurate.

[Insert Table 1: Monte Carlo Experiments from Average Runs]

Table 1 indicates that the average and maximum per period differences between the five experiments fall as the number of runs rises. For 2000 runs, the maximum difference in populations is less than $7 \%$, while the average difference is about $2 \%$. For the resource stock, the numbers are about $1 \%$ and $0.6 \%$, respectively. Hence, analyzing the mean behavior of the system based on 2000 runs seems to be a reasonable proxy of the true underlying mean tendency of the win system.

\section{References}

[1] Anderton, C. H., R. A. Anderton and J. Carter (1999), "Economic Activity in the Shadow of Conflict," Economic Inquiry, 37: 166-179.

[2] Baye, M. and H. Hoppe (2003), "The Strategic Equivalence of rent seeking, innovation, and patent-race games," Games and Economic Behavior, 44: 217-226.

[3] Beevor, Antony (1999), Stalingrad, New York: Penguin Books.

[4] Brander, J. A. and M. S. Taylor (1998), "The Simple Economics of Easter Island: a Ricardo-Malthus Model of Renewable Resource Use," American Economic Review.

[5] Brito, D. L. and M. D. Intriligator (1985), "Conflict, War and Redistribution," American Political Science Review, 79: 943-957.

[6] Clark, C. W. (1990), Mathematical Bioeconomics: The Optimal Management of Renewable Resources, New York: Wiley.

[7] Fullerton, R. L. and R. P. McAfee (1999), "Auctioning Entry into Tournaments," Journal of Political Economy, 107: 573-605.

[8] Garfinkel, M. R. and S. Skaperdas (2000), "Conflict without Perception or Incomplete Information: How the Future Matters," Journal of Conflict Resolution, 44: 793-807.

[9] Grossman, H. I. and M. Kim (1995), "Swords or Plowshares? A Theory of the Security of Claims to Property," Journal of Political Economy, 103: 275-288.

[10] Heerink, N. (1994), Population Growth, Distribution, and Economic Development: Theory, Methodology and Empirical Results, Berlin: Springer-Verlag. 
[11] Hirshleifer, J. (1988), "The Analytics of Continuing Conflict," Synthese, 76: 201-233.

[12] Hirshleifer, J. (1989), "The Dimensions of Power as Illustrated in a Steady-State Model of Conflict," A Rand Note, N-2889-PCT.

[13] Hirshleifer, J. (1991), "The Paradox of Power," Economics and Politics, 3: 177-200.

[14] Hirshleifer, J. (1995), "Anarchy and its Breakdown," Journal of Political Economy, 103: $15-40$.

[15] Homer-Dixon, F. Thomas (1999), Environment, Scarcity and Conflict, Princeton, NJ: Princeton University Press.

[16] Jablonski, Edward (1995), A Pictorial History of the World War II Years, New York: Wings Books.

[17] Maxwell, J. W. and R. Reuveny (2000), "Resource Scarcity and Conflict in Developing Countries," Journal of Peace Research, 37: 301-322.

[18] Maxwell, J. W. and R. Reuveny (2004), "Continuing Conflict," Journal of Economic Behavior and Organization, forthcoming.

[19] Neary, H. M. (1997), "Equilibrium Structure in an Economic Model of Conflict," Economic Inquiry, XXXV: 480-494.

[20] Nitzan, S. (1994), "Modeling Rent-Seeking Contests," European Journal of Political Economy, 10: 41-60.

[21] Prange, W. G. (1983) Miracle at Midway, New York: Penguin Books.

[22] Powell, R. (1993), "Guns, butter, and anarchy," American Political Science Review 87: $14-132$.

[23] Reuveny, R. and J. W. Maxwell (2001), "Conflict and Renewable Resources," Journal of Conflict Resolution, 45: 719-742.

[24] Skaperdas, S. (1992), "Cooperation, Conflict and Power in the Absence of Property Rights," American Economic Review, 82: 720-739.

[25] Skaperdas, S. (1996), "Contest Success Functions," Economic Theory, 7: 283-190

[26] Tullock, Gordon (1980), "Efficient Rent Seeking," in James M. Buchanan, Robert D. Tollison, and Gordon Tullock, eds., Toward a theory of the rent-seeking society. College Station, TX: Texas A \& M University Press, 97-112.

[27] Usher, D. (1989), "The Dynastic Cycle and the Stationary State," American Economic Review, 79: 1031-1044. 
[28] Wallace, James, and Jim Erickson (1992) Hard Drive:Bill Gates and the Making of the Microsoft Empire, New York:John Wiley and Sons. 
Figure 1: Populations from a Single Run

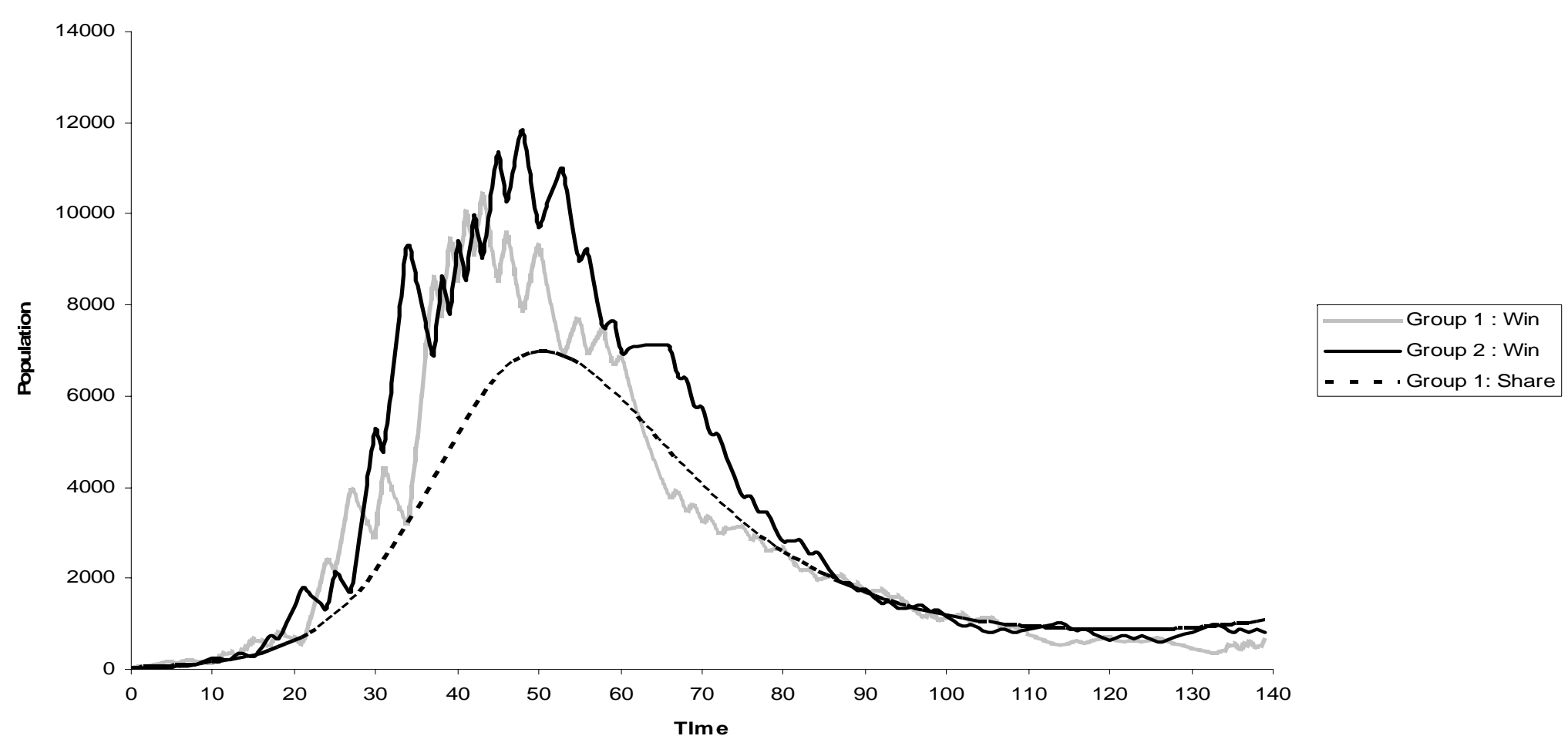


Figure 2: Cornering from a Single Run

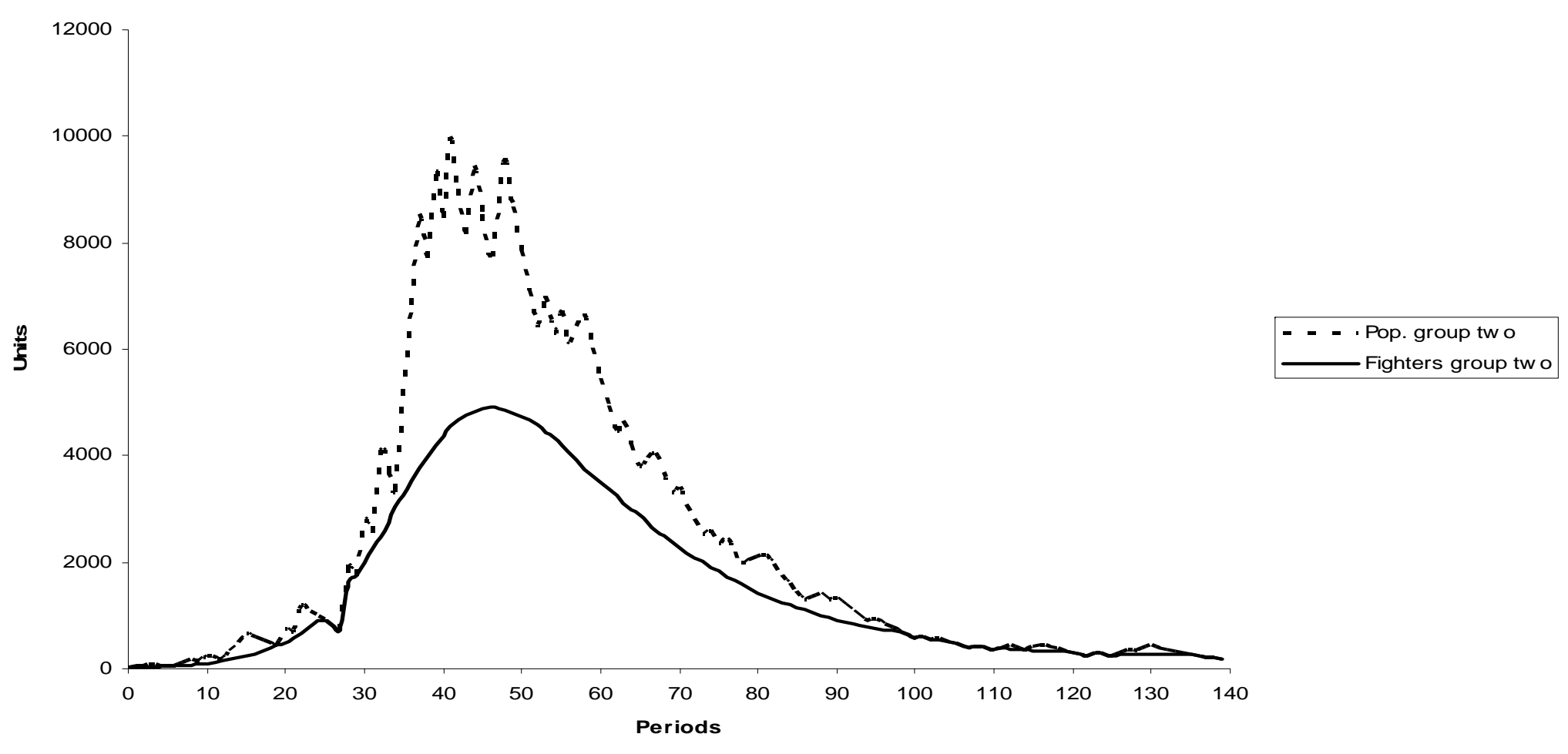


Figure 3: Death from a Single Run

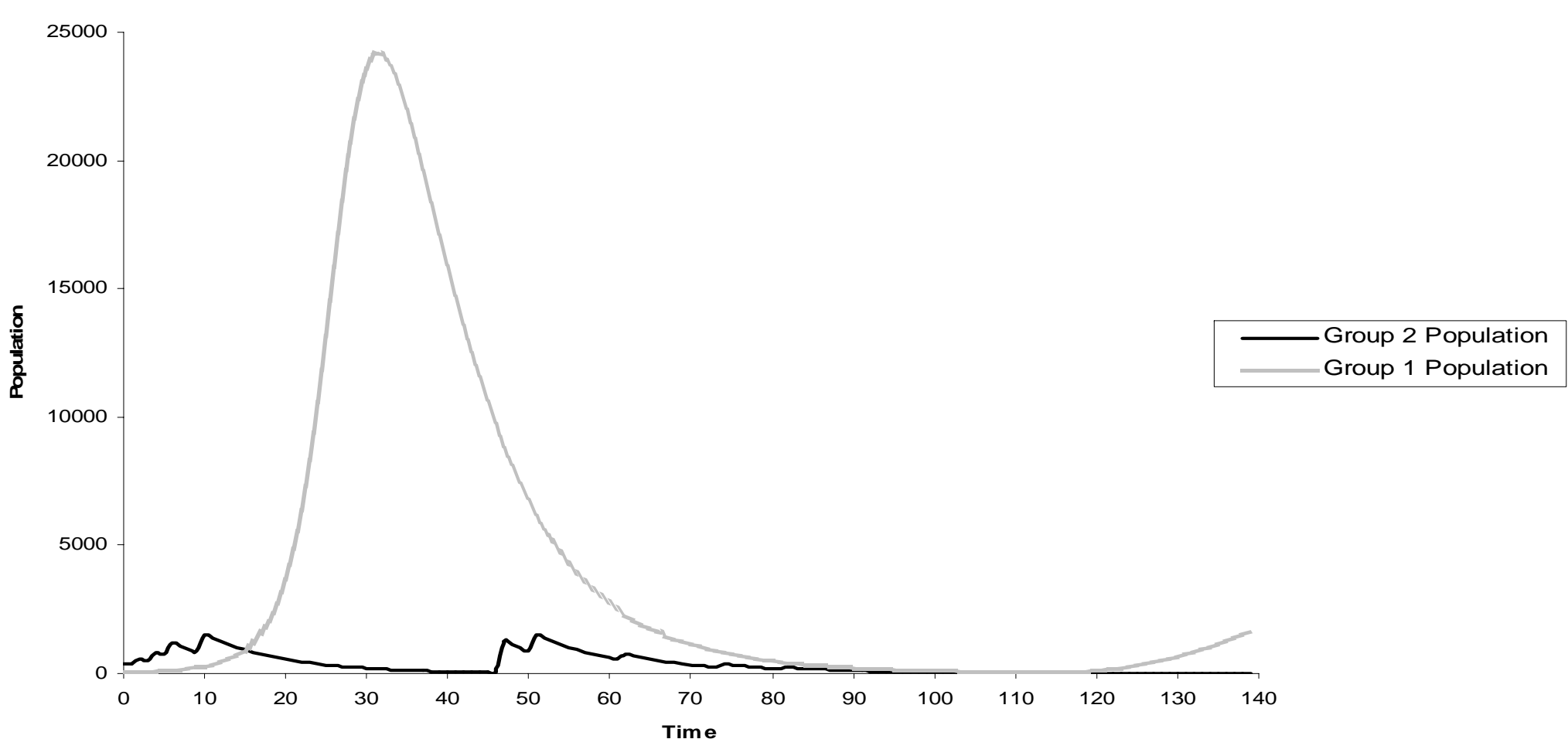


Figure 4: Population Means

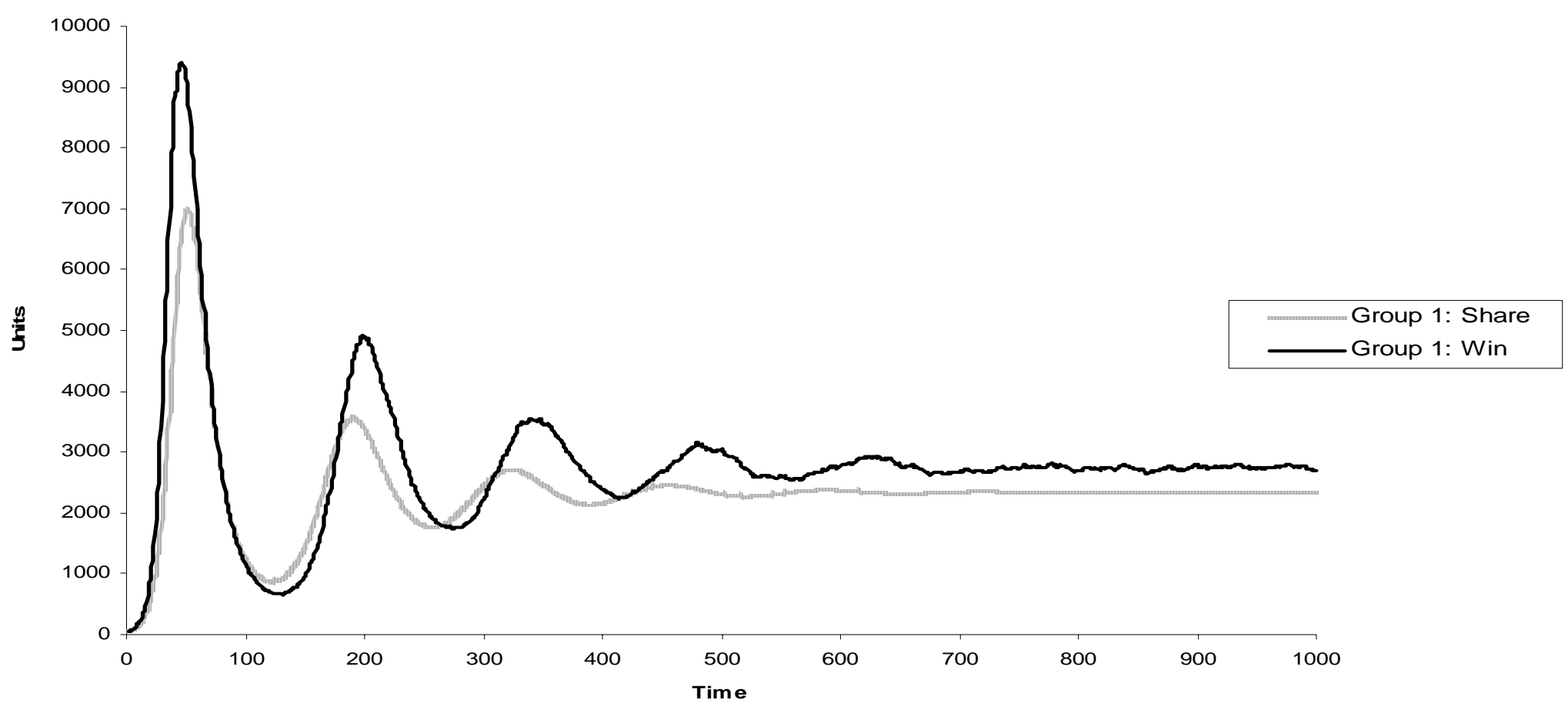


Figure 5: Fighting Allocation Means

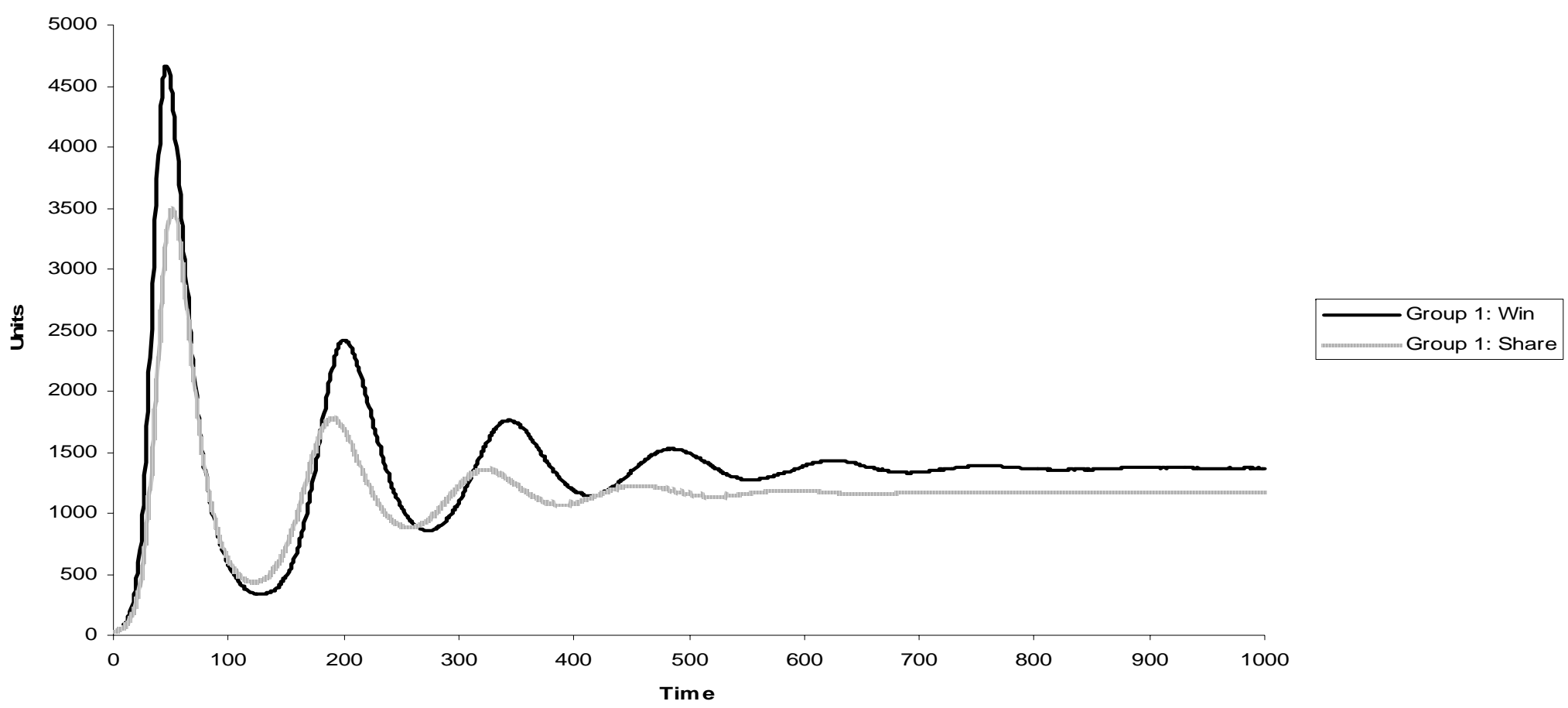


Figure 6: Resource Means

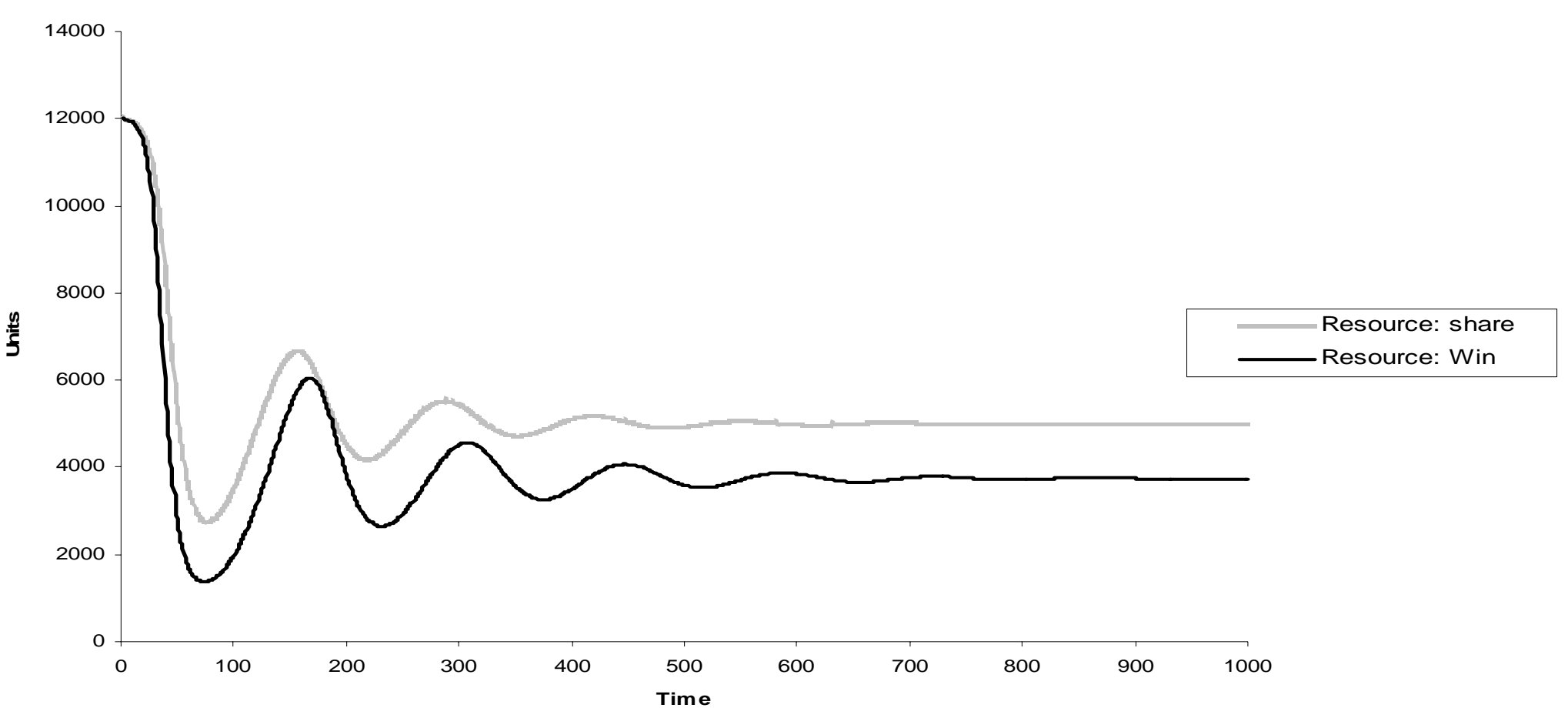

